\title{
NISTIR $90-4299$
}

\section{NEW NIST PUBLICATION}

October 1990

\section{EVALUATION OF}

NVLAP PERSONNEL

DOSIMETRY TESTING

\section{LABORATORY:}

X-RAYS

\section{H. T. Heaton, II}

U.S. DEPARTMENT OF COMMERCE Natlonal Instltute of Standards and Tochnology Natlonal Measurement Laboratory Center for Radlation Research Galthorsburg, MD 20899

U.S. DEPARTMENT OF COMMERCE Robert A. Mosbacher, Secretary NATIONAL INSTITUTE OF STANDARDS AND TECHNOLOGY

John W. Lyons, Director 



\section{EVALUATION OF}

NVLAP PERSONNEL

DOSIMETRY TESTING

LABORATORY:

X-RAYS

\section{H. T. Heaton, II}

U.S. DEPARTMENT OF COMMERCE National institute of Standards and Tochnology

Natlonal Measurement Laboratory Center for Radlation Resoarch Galthersburg, MD 20899

Aprll 1990

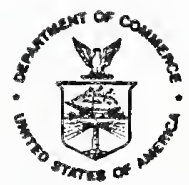

U.S. DEPARTMENT OF COMMERCE Robert A. Mosbacher, Secretary NATIONAL INSTITUTE OF STANDARDS AND TECHNOLOGY

John W. Lyona, Director 



\title{
EVALUATION OF NVLAP PERSONNEL DOSIMETRY TESTING LABORATORY: $X-R A Y S$
}

H. T. Heaton, II

National Institute of Standards and Technology office of Radiation Measurement

Gaithersburg, MD 20899

\begin{abstract}
The Pacific Northwest Laboratory (PNL) is the testing laboratory for the National Voluntary Laboratory Accreditation Program (NVLAP) for personnel radiation dosimeters. The Center for Radiation Research (CRR) has an agreement with NVLAP to monitor this laboratory to ensure that their reference radiation fields are known with sufficient accuracy. This report describes the measurements made by CRR personnel at PNL to ensure that their M30 and M150 x-ray beams are known within the specified accuracy.
\end{abstract}

\section{INTRODUCTION}

One of the programs administered by the National Voluntary Laboratory Accreditation Program (NVLAP) is to accredit processors of personnel radiation dosimeters. As part of this accreditation process, the processor sends personnel dosimeters to be irradiated to known (but undisclosed) doses at a testing laboratory. The processor then determines the administered dose. The difference between the dose delivered by the testing laboratory and reported by the processor must meet the performance criteria specified in ANSI N13.11-1983 ("Personnel Dosimetry Performance - Criteria for Testing"). The Center for Radiation Research (CRR) has an agreement with NVLAP to monitor the testing laboratory to ensure that their radiation fields are within the required accuracy. The testing laboratory for the dosimeter irradiations is Pacific Northwest Laboratory (PNL). This report describes the measurements made by CRR personnel at PNL to determine that the exposure at a specified distance was sufficiently well known for the M30 and M150 x-ray radiation beams. Since the conversion factor, $C_{x}$, from exposure to dose equivalent at specified depths depends on beam quality, the half-value layers for these beams were also measured.

On May 31-June 1, 1989, personnel from the Office of Radiation Measurement (ORM) within the Center for Radiation Research conducted two series of measurements on the Philips* model $323-\mathrm{kVp}$ $x-r a y$ unit at PNL to evaluate the M30 and M150 x-ray beams. For this evaluation, the equipment used by ORM to monitor measurement quality assurance performance test transfer standards was first characterized in the $M 30$ and M150 x-ray beams maintained by the 
Radiation Interaction and Dosimetry (RID) Group at CRR. The equipment was shipped to PNL and the same series of measurements was repeated using their equivalent beams. This provides a direct intercomparison of the $x$-ray beams at PNL against the corresponding beams at NIST.

\section{EVALUATION METHOD}

For each x-ray beam, the evaluation consisted of two classes of measurements. The first class was an intercomparison of exposure rate and total exposure in the absence of the phantom at the location where the front surface of the phantom would normally be placed. The exposure rate and exposure measurements involved comparing the values obtained by PNL using their transmission monitor connected to a Victoreen model 500 electrometer, with the value obtained by ORM using an Exradin A2 ion chamber connected to the ORM charge measuring system and ORM computer program for calculating exposure or exposure rate. The only common piece of equipment between the two systems was the PNL barometer. However, the offset between the PNL barometer and the ORM barometer obtained from an earlier barometer intercomparison was used in the computer code to calculate the actual pressure correction.

The second class of measurements was of half-value layer (HVL) and homogeneity coefficient (HC). For both the M30 and M150 beams, the same sequence of added filters was used to measure the transmission at both NIST and PNL. This allowed a point-by-point intercomparison of the beams as a function of added aluminum as well as a calculation of the HVL and HC values using the ORM computer code.

\section{SUMMARY OF RESULTS}

The results of the measurements made during the evaluation are summarized in Tables 1 and 2. Details of the measurements and conclusions are given in the sections following the results.

Table 1 summarizes the $M 30$ and M150 x-ray beam exposure and exposure rate measured by PNL using their transmission monitor and by NIST using the ORM system.

Table 1

Intercomparison of exposure rate $(R / h)$ and exposure (mR) Exposure rate $(R / h)$

$\begin{array}{lllc}\text { Beam } & \text { PNL } & \text { NIST } & \text { o difference(a) } \\ \text { M30 } & 58.8 & 61.3 & -4.1 \\ \text { M150 } & 40.36 & 40.42 & -0.2\end{array}$

Exposure (mR)

$\begin{array}{cccc}\text { Beam } & \text { PNL } & \text { NIST } & \text { difference }(a) \\ \text { M30 } & 443.5 & 461.1 & -3.8 \\ \text { M150 } & 708 & 708.6 & -0.2 \\ \text { erence } & =100 *(\text { PNL value } & - \text { NIST } & \text { value)/NIST value }\end{array}$

The differences measured for the M30 beam are acceptable but 
larger than expected. The values measured at PNL were corrected for the A2 response corresponding to the HVL of their beam. (See the section on 'MEASUREMENTS MADE AT NIST' for a further discussion of similar measurements comparing ORM and RID values.)

Table 2 summarizes the half-value layer and homogeneity coefficient measurements. The first set of "PNL" values are their determination of their beam parameters and the second set are the corresponding values of their parameters determined with the ORM system. The NIST values are those reported in NIST SP-250. (See the section on 'MEASUREMENTS MADE AT NIST' for a further discussion of the HVL of the NIST M3O beam.)

Table 2

Intercomparison of HVL and $\mathrm{HC}$

\begin{tabular}{|c|c|c|c|c|c|c|}
\hline \multicolumn{2}{|c|}{$\begin{array}{l}\text { Beam } \\
\text { Code }\end{array}$} & $\begin{array}{c}\text { PNL } \\
(\text { PNL) }\end{array}$ & $\begin{array}{c}\text { PNL } \\
(\text { ORM })\end{array}$ & NIST & $\begin{array}{c}\text { difference (a) } \\
\text { (PNL) }\end{array}$ & $\begin{array}{l}\text { difference }(2) \\
\text { (ORM) }\end{array}$ \\
\hline M30 & HVL & .365 & .351 & .36 & 1.4 & -2.5 \\
\hline & $\mathrm{HC}$ & 69 & 62.9 & 64 & 7.8 & -1.7 \\
\hline M150 & HVL & 9.95 & 10.16 & 10.2 & -2.5 & -0.4 \\
\hline & $\mathrm{HC}$ & 87 & 87 & 87 & 0 & 0 \\
\hline
\end{tabular}

(a) of difference $=100 *($ PNL(PNL) value - NIST value)/NIST value

(2) \& difference $=100 *($ PNL(ORM) value - NIST value)/NIST value

These results indicate satisfactory agreement between the $x-r a y$ beam parameters for the PNL beams and those reported in SP-250 for the corresponding NIST beams.

\section{ORM EQUIPMENT USED IN EVALUATION}

The following equipment was used in the evaluation:

1) An Exradin A2 ionization chamber SN 138. M30 beam calibration factor from calibration report DG8364/85 (The reported calibration factors were multiplied by 0.998 to account for a humidity correction applied beginning January 1, 1986). M150 beam calibration factor from calibration report DG8932/88.

2) A Keithley 616 electrometer SN 65259. This was calibrated using a Keithley 261 picoampere source and the ORM developed computer code(1) for $261 / 616$ calibration in Sept 1986 . A QC check of the 261/616 response was made at PNL to ensure that the correction factor for the electrometer charge range had not changed to the extent that it would seriously impact the results. This was verified when the electrometer was recalibrated in October 1989.

3) The tine interval was determined with the NIST built "shutter Timing Control Unit". A QC check of the timer unit was made after its return to NIST.

4) The exposure, exposure rate, half-value layer and homogeneity coefficient were determined using the computer code developed by ORM(1) but on a computer supplied by PNL. 
MEASUREMENTS MADE AT NIST

Before the ORM system was sent to PNL, it was first used with the $x$-ray beams of the Radiation Interactions and Dosimetry Group (RID) to compare the entire system directly against the national standards. The first series of measurements compared the exposure and exposure rate measured using the national standard and the ORM system. The results are shown in Table 3 . In this table, the results labeled "RID" were done with the free air chamber-RID exposure system. The results labeled "ORM" are the corresponding results using the ORM system.

Table 3

Intercomparison of exposure rate (mR/s) and exposure (mR) at NIST

Exposure rate $(\mathrm{mR} / \mathrm{s})$

$\begin{array}{lccc}\text { Beam } & \text { ORM } & \text { RID } & \text { o difference(a) } \\ \text { M30 } & 73.51 & 73.70 & -0.16 \\ \text { M150 } & 31.46 & 31.51 & -0.15\end{array}$

Exposure (mR)

$\begin{array}{lccc}\text { Beam } & \text { ORM } & \text { RID } & \text { o difference(a) } \\ \text { M30 } & 7354.6 & 7375.5 & -0.24 \\ \text { M150 } & 946.0 & 947.7 & -0.18\end{array}$

The second set of measurements compared the HVL and HC of the M30 and M150 beams using both the free air chamber and the A2 ion chamber-ORM system. For both ion chamber measurements, the same sequence of added filter material was used. The filter material is the normal added aluminum filter material which RID uses for their x-ray beam characterization. The primary objective of this set of measurements was to determine how well the transmission curve measured with the A2 ion chamber could be corrected for its energy dependence. The uncertainty for the HVL and HC values listed in Table 4 is only the statistical uncertainty of the fit at the desired point for a 958 confidence interval (as are all the uncertainties 1 isted in this report). For the M30 beam, the ion chamber was $50 \mathrm{~cm}$ from the source with the added filter material located $25 \mathrm{~cm}$ from the source. For the M150 beam, the corresponding distances were $100 \mathrm{~cm}$ and $50 \mathrm{~cm}$ respectively.

Table 4

Intercomparison of HVL and HC Measurements Made at NIST

$\begin{array}{clccc}\begin{array}{c}\text { Beam } \\ \text { Code }\end{array} & & \text { A2 } & \text { FAC } & \text { o difference(a) } \\ \text { M30 } & \text { HVL } & 0.381 \pm 0.005 & 0.373 \pm 0.005 & 2.1 \\ & \text { HC } & 65.1 \pm 1.4 & 63.8 \pm 1.7 & 2.0 \\ \text { M150 } & \text { HVL } & 10.22 \pm 0.05 & 10.22 \pm 0.05 & 0 \\ & \text { HC } & 87.3 \pm 0.8 & 87.2 \pm 0.8 & 0.1\end{array}$

(a) $z$ difference $=100 *(A 2$ value - FAC value)/FAC value 
Even though there is a 2.18 difference between the HVL of the M30 beam determined with the A2 and the FAC, the difference is not statistically significant at the 958 confidence level. There is concern that the value measured with the free air chamber and the RID added filter material disagrees with the value for this NIST beam as reported in Table 2 by $3.6 \%$. The cause of this difference is still under investigation. The results of this study may cause the PNL HVL and HC values for the $M 30$ beam to be revised.

The FAC results for the $M 30$ beam reported in Table 4 have been corrected for the relative change in air attenuation correction due to spectral changes resulting from the added filter material (The uncorrected HVI and HC are $0.383 \pm 0.005$ and $64.5 \pm 1.7$ ). The relative air attenuation correction calculation used fluence spectrum C21 from W. W. Seelentag etal.(2) of GSF. Each point on the fluence spectrum was first corrected for air path attenuation assuming that the GSF air path was $40 \mathrm{~cm}$ and air density for pressure, temperature and humidity of $760 \mathrm{~mm} \mathrm{Hg}, 22^{\circ} \mathrm{C}$ and $30 \%$. Then, for each point in the transmission measurement, the fluence through the added filter and a $43-\mathrm{cm}$ air path was calculated. The air attenuation correction inside the FAC is the ratio of the integral exp $(-\mu * 1) * p s i * d E$ and integral of psi*dE where psi is the exposure per energy interval at the entrance of the FAC, $\mu$ is the air attenuation coefficient as a function of energy, and $l$ is the path in the FAC $(12.7 \mathrm{~cm})$. The relative air attenuation correction changed by 2.0 over the range of added filter material. Finally, each transmission point was corrected for the appropriate air attenuation and the resulting curve used to determine the HVL and HC. In all these calculations, there was no correction for buildup in air, just attenuation. The calculated FAC air attenuation correction agrees within about $0.1 \%$ with the value experimentally measured by RID for no added filter material.

\section{BEAM CHARACTERTZATION MEASUREMENTS AT PNL}

As already indicated, the HVL and HC for the M30 and M150 beams at PNL were measured with the ORM system using the same added aluminum filter material in the same sequence as at NIST. All measurements at PNL were made at 1 meter from the source, the location at the surface of the phantom for normal personnel dosimeter irradiation. Their normal collimator is designed so that the full $30 \mathrm{~cm}$ by $30 \mathrm{~cm}$ face of the phantom is irradiated when placed at the 1 meter location. Since the useful area of the added filter material is about $5 \mathrm{~cm}$ diameter, it was necessary to replace the normal collimator with one having a smaller opening. Even with the smaller collimator, a radiograph showed that the beam size was defined by the entrance hole of the device used to hold the added filter material. The beam was limited to $4.5 \mathrm{~cm}$ diameter by placing the normal collimator $6 \mathrm{~cm}$ in front of the 
filter holder. The result of this more tightly collimated beam on HVL and HC was not investigated. A radiograph of this beam showed a penumbra of about $0.1 \mathrm{~cm}$ and some evidence of beam mis-alignment but this should not have effected the measured results.

It was necessary to apply several corrections to the M30 beam transmission measurements. About half way through the measurements for this beam there was a break for lunch. After lunch, the exposure rate measured with both the A2 and the transmission monitor was about a percent lower. Due to the lack of significant digits in the readout for $x$-ray tube current and voltage, it could not be ascertained what parameter had varied, so no changes were made to the $x$-ray unit controls. The transmission curve was analyzed several ways to determine the HVL and HC: 1) making no correction for the change in transmission, $0.365 \pm 0.004$ and $65.3 \pm 1.2 ; 2$ ) assuming all transmission measurements made after lunch should be corrected by a constant $1.1 \%, 0.357 \pm 0.009$ and $63.3 \pm 2.5$ and 3 ) assuming that the $x$-ray unit returned smoothly to its before lunch condition by the end of the measurements so that a varying correction had to be applied, $0.361 \pm 0.005$ and $64.6 \pm 1.4$. To test the validity of these assumptions, personnel from PNL repeated the measurement for the $M 30$ beam using the ORM system. The corresponding results were $0.358 \pm 0.004$ and $63.9 \pm 1.2$. As in Table 4, the uncertainties given here includes only the statistical component and corresponds to the standard error of the mean for a 958 confidence interval on the regression fit to the transmission values of 0.5 and 0.25 .

Figure 1 shows the ratio of the transmission measured at PNL for these various cases to that measured at NIST. Up to about the $1.32 \mathrm{~mm}$ added Al point, the curve for the smoothly varying $x-r a y$ correction agrees better with second measurement result. The weighted HVL and HC results for these two cases are $0.359 \pm 0.003$

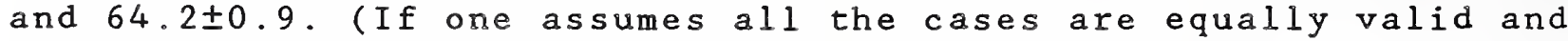
statistically independent, the corresponding results are $0.361 \pm 0.002$ and $64.5 \pm 0.7$.

In addition to the correction for the change in transmission, one should also correct the results for differences measured with the FAC and with the A2. Assuming that the percentage change for the beams at NIST and PNL is the same, the PNL HVL should be multiplied by 0.979 and the HC by 0.980 . Thus, the best estimate of the HVL and HC for the PNL M30 beam are $0.351 \pm 0.003$ and $62.9 \pm 0.9$.

It should be noted that Figure 1 also shows that there is a real difference between the M30 beams at NIST and PNL since the ratio of the measured transmissions increases in a relatively smooth manner. This statement depends only on the ratio of A2 charge measurements at both places with the other corrections canceling. 
Figure 2 shows the corresponding ratio for the M150 beam. Again the ratio of the transmission measured at NIST using the oRM instrumentation and the transmission measured at PNL is shown. In this case there is no practical difference in these beams as the transmission ratios agree over the entire range of added filter material to within a percent.

\section{IMPACT OF BEAM QUALITY ON CONVERSION FACTOR}

The accuracy requirement on the reference radiation fields in ANSI standard N13.11-1983(3) assumes that there is no additional uncertainty due to the conversion factors, $C_{x}$, for exposure to dose equivalent. The conversion factors are specified for beams corresponding to NIST beams so if the beam quality of the testing laboratory does not match the corresponding beam at NIST, the conversion factor specified in the standard will not be appropriate for the testing laboratory. Table 5 lists the $C_{x}$ factors for $x$-ray beams for the shallow and deep dose equivalent as listed in the ANSI standard.

\section{Table 5}

Conversion factors from exposure to dose equivalent

$\begin{array}{ccc}\text { Beam HVL } & \text { shallow } & \text { deep } \\ 0.36 & 0.92 & 0.40 \\ 1.02 & 1.02 & 0.72 \\ 1.86 & 1.14 & 0.95 \\ 2.79 & 1.14 & 0.98 \\ 5.03 & 1.30 & 1.20 \\ 10.25 & 1.43 & 1.38\end{array}$

To determine the value of $C x$ for other $x$-ray beams, it is necessary to know the actual spectrum of that $x$-ray beam and to form a spectrum weighted average of the monoenergtic $C x$ factors given in the standard. To try to estimate the uncertainty resulting from PNL's $x$-ray beams being different from the corresponding beams at NIST, it was assumed that the HVL of the beam represented the beam quality and a least-squares fit was made to the $\log$ of the conversion factor and the log of the HVL, i.e.

$$
\ln \left(\mathrm{C}_{\mathrm{x}}\right)=\mathrm{b}_{0}+\mathrm{b}_{1} * \ln (\mathrm{HVL})+\mathrm{b}_{2} * \ln \wedge 2(\mathrm{HVL})+\mathrm{b}_{3} * \ln \wedge 3(\mathrm{HVL})
$$

where for the shallow dose the values of the coefficients are $0.02397,0.12191,0.01416$ and -0.00195 and for the deep dose the corresponding values are $-0.32505,0.43849,-0.11687$, and 0.02079 . These conversion factors as a function of HVL are shown in figure 3. From Table 5 it can be seen that the conversion factors for the beams with HVL equal 1.86 and 2.79 are nearly the same. Hence, the assumption that this model represents the relationship between $C x$ and beam quality is not very good. The resulting $C x$ values should only be used to estimate uncertainties in $C x$ and not 
revised $C x$ values used to determine the reported dose equivalent to the personnel dosimeters.

With this caveat, using this model for the relationship between Cx and HVL, the fit values of the conversion factors for a beam with HVL $=0.36$ are 0.9197 for the shallow dose and 0.3996 for the deep dose. For a beam with HVL equal to 0.351 , the corresponding conversion factors are 0.9177 and 0.3922 . Thus, to the extent that this model can be used to represent the uncertainty in the relationship between the conversion factor and $x$-ray beam HVL, the difference in the conversion factors for a beam with HVL $=0.36$ and a beam actually having a HVL $=0.351$ will result in assigning a dose equivalent that is 1.98 too high for the deep dose and $0.2 \%$ too high for the shallow dose. One may treat these differences as an estimate of the uncertainty in the assigned dose equivalent due to differences between the NIST and PNL $x$-ray beams.

\section{SUMMARY}

Measurements made by NIST personnel at the testing lab used by NVLAP for personnel dosimeter irradiations demonstrate that they can determine that the exposure rate and exposure measurements from the M30 and M150 x-ray beams within the required accuracy. Furthermore, measurements of the half-value layers and homogeneity coefficients of these beams show that they are in satisfactory agreement with the corresponding NIST beams so that no significant additional uncertainty should be introduced into the values of the dose equivalent this testing lab assigns to the irradiated dosimeters.

\section{REFERENCES}

(1) Heaton, II, H. T., "Secondary-Level Laboratories: Methodology for a Calibration Program", draft form for an NIST internal report

(2) Seelentag, W. W., W. Panzer, G. Drexler, L Platz, and F. Santer, "A Catalogue of Spectra used for Calibration of Dosemeters", Gesellschaft fur Strahlen-und Umweltforschung mbH Muchen Institut for Strahlenschutz, GSF-Bricht S 560 (1979)

(3) ANSI N13.11-1983, "American National Standard for Dosimetry Personnel Dosimetry Performance Criteria for Testing", American National Standards Institute, New York, NY

* Commercial equipment is indicated in this report to specify the measurement conditions. It does not represent endorsement by NIST . 
Figure 1. At both NIST and PNL the transmission was measured as a function of accurately known added thicknesses of aluminum. For the M30 x-ray beam, this figure shows the ratio of the transmission for a particular amount of added aluminum made at PNL to the transmission for the same amount of aluminum made at NIST. Two sets of transmission were made for this beam, labeled Run 1 and Run 2. See text for an explanation of the modifications made to Run 1 .

Figure 2. Ratio of transmission for the M150 x-ray beam measured at NIST and PNL using the same ion chamber and same filter material.

Figure 3. The individual data points are the values of the $x-r a y$ beam conversion factors from exposure to dose equivalent as reported in ANSI 13.11-1983. The upper set is for the shallow dose factors and the lower curve is for the deep dose factors. The solid curves are the fits assuming the functional form between the conversion factor and $x$-ray beam HVL discussed in the text. 


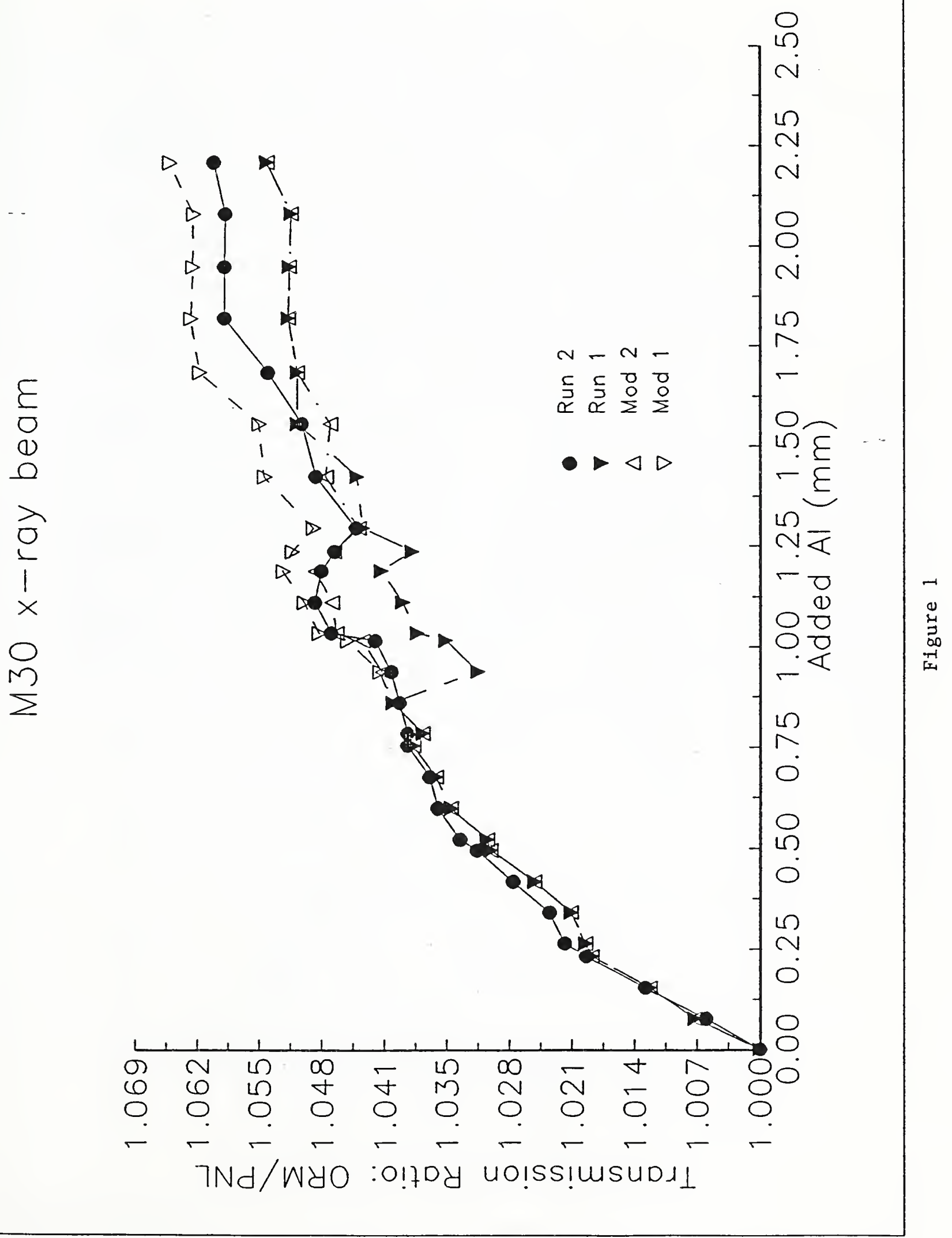




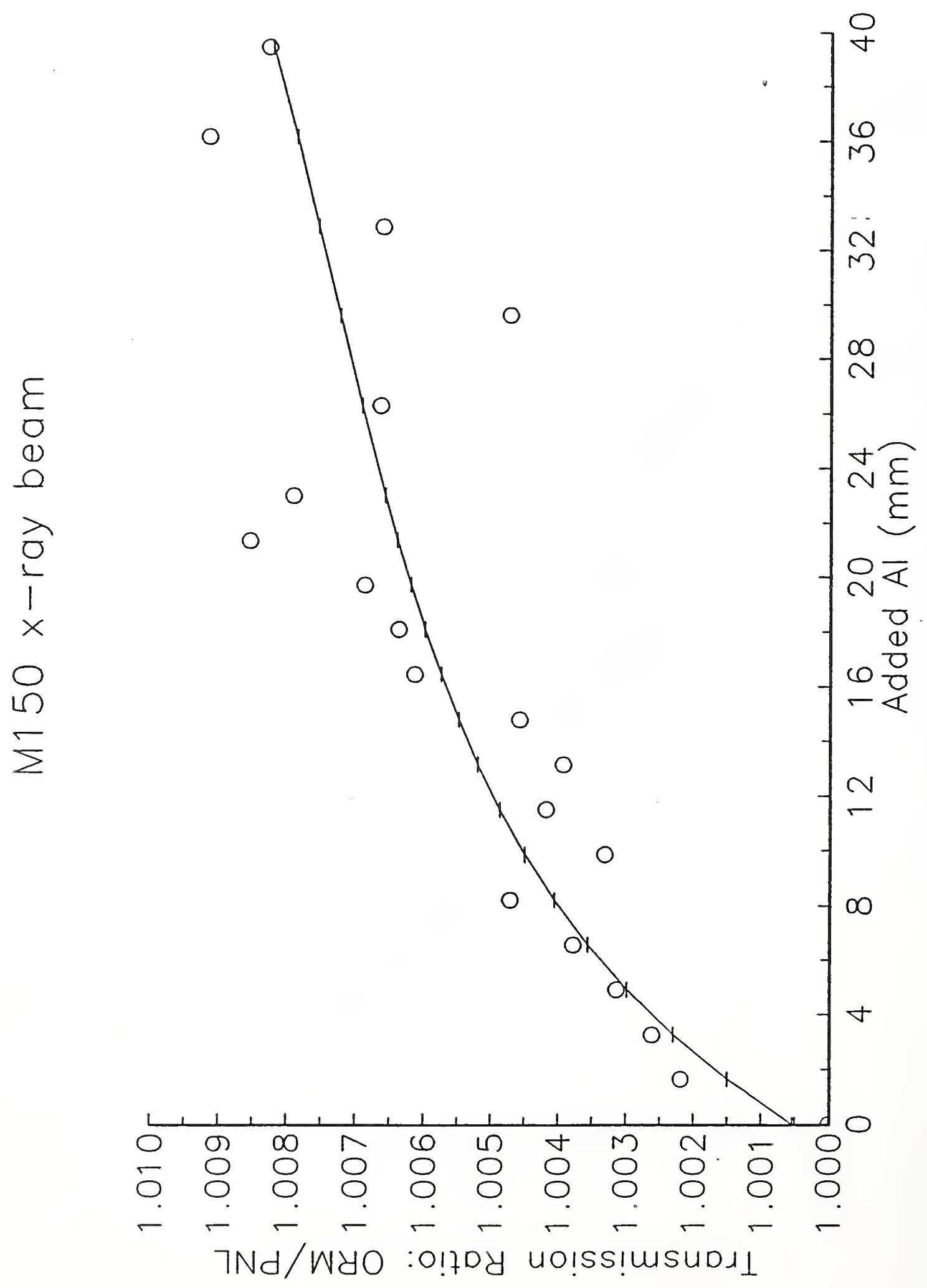




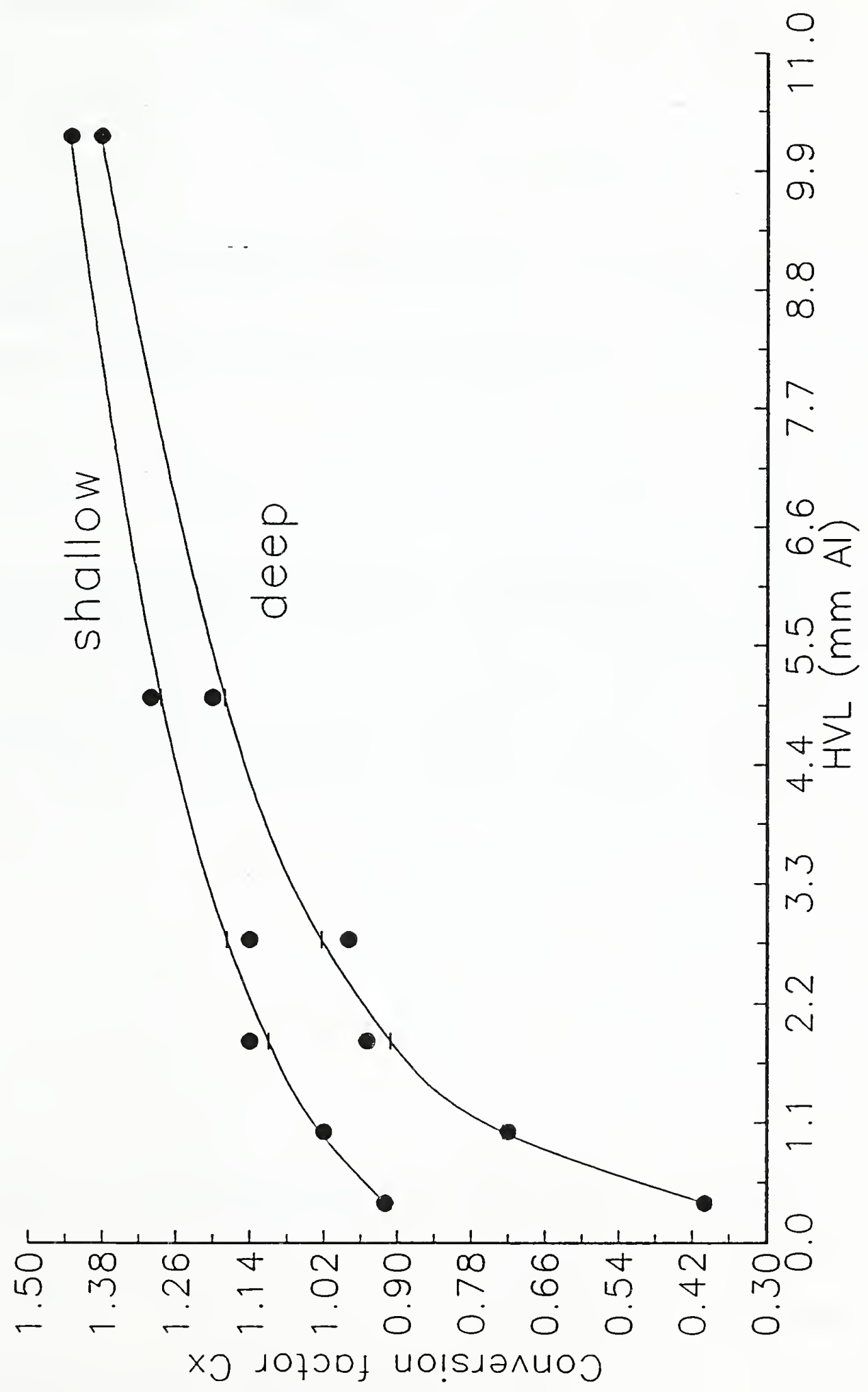





\begin{tabular}{|c|c|c|}
\hline \multirow[t]{3}{*}{$\begin{array}{l}\text { NIST-114A } \\
\text { (REV. 3-89) }\end{array}$} & \multirow{3}{*}{$\begin{array}{l}\text { U.S. DEPARTMENT OF COMMERCE } \\
\text { NATIONAL INSTITUTE OF STANDARDS AND TECHNOLOGY } \\
\text { BIBLIOGRAPHIC DATA SHEET }\end{array}$} & $\begin{array}{l}\text { 1. PUBLICATION OR REPORT NUMBEF } \\
\text { NISTIR 90-4299 }\end{array}$ \\
\hline & & 2. PERFORMING ORGANIZATION REPOAT NUMBER \\
\hline & & \begin{tabular}{|l} 
\\
3. PUBLCATION DATE \\
APRIL 1990
\end{tabular} \\
\hline
\end{tabular}

4. TITLE AND SUBTITLE

Evaluation of NVLAP Personnel Dosimetry Testing

Laboratory: $\mathrm{X}$-rays

5. AUTHOR(S)

H. T. Heaton, II

6. PERforming ORGanization (IF JOINT OR OTHER THAN NIST, SEE INSTRUCTIONS)

U.S. DEPARTMENT OF COMMERCE

NATIONAL INSTITUTE OF STANDARDS AND TECHNOLOGY

GAITHERSBURG, MD 20899

7. CONTRACT/GRANT NUMBEA

8. TYPE OF REPORT AND PERIOD COVERED

9. SPONSORING ORGANIZATION NAME AND COMPLETE ADORESS (STREET, CITY, STATE, ZIP)

10. SUPPLEMENTAAY NOTES

DOCUMENT DESCRIBES A COMPUTER PROGRAM; SF.185, FIPS SOFTWARE SUMMARY, IS ATTACHED.

11. ABSTRACT (A 2OO-WORD OR LESS FACTUAL SUMMAPY OF MOST SIGNIFICANT INFORMATION. IF DOCUMENT INCLUDES A SIGNIFICANT BIBLIOGRAPHY OR LTERATURE SURVEY, MENTION IT HERE.)

The Pacific Northwest Laboratory (PNL) is the testing laboratory for the National Voluntary Laboratory Accreditation Program (NVLAP) for personnel radiation dosimeters. The Center for Radiation Research (CRR) has an agreement with NVLAP to monitor this lab to ensure their reference radiation fields are known. This report describes the measurements made by CRR personnel at PNL to make sure that their M150 $\mathrm{x}$-ray beams are known within the specified accuracy.

12. KEY WORDS (6 TO 12 ENTRIES; ALPHABETICAL ORDEA; CAPITALUZE ONLY PROPER NAMES; AND SEPARATE KEY WORDS BY SEMICOLONS) irradiation; NVLAP; personnel dosimetry; proficiency testing; radiation; testing laboratory; $\mathrm{X}$-rays 

